\title{
Activity of the renin-angiotensin system in acute severe asthma and the effect of angiotensin II on lung function
}

Evelyn A Millar, Robert M Angus, Geoffrey Hulks, J J Morton, John M C Connell, Neil C Thomson

\begin{abstract}
Background - The activity of the reninangiotensin system in asthma has not been studied previously and the effect of angiotensin II (AII) on bronchomotor tone in vivo is unknown.

Methods - Plasma levels of renin and AII levels were measured in 20 patients with acute severe asthma, nine with mild asthma, 10 with severe chronic asthma, and 16 normal volunteers. The effect of AII, given as an intravenous infusion, on bronchomotor tone was also investigated in eight mild asthmatic patients.

Results - In acute severe asthma plasma levels of renin [median (interquartile range)] were elevated on days 1,2 , and 5 after admission [48.7 (24-79), 44.2 (15-75), and $45 \cdot 5(21-70) \mu \mathrm{U} / \mathrm{ml}$, respectively]. Plasma AII levels were significantly elevated at day 5 [56 (12-109) $\mathrm{pg} / \mathrm{ml}$. In the second study a bronchoconstrictor response to intravenous AII was seen with a mean (SE) maximal fall in $\mathrm{FEV}_{1}$ of 0.34 $(0 \cdot 13)$ litres or $12.4(3.3) \%$ from baseline following the high dose infusion of AII (8 $\mathrm{ng} / \mathrm{kg} / \mathrm{min})$ with a corresponding plasma AII concentration of $121 \cdot 3 \mathrm{pg} / \mathrm{ml}$. Conclusions - The renin-angiotensin system is activated in acute asthma and AII causes bronchoconstriction in vivo in man. These observations suggest that in some patients AII may contribute to bronchoconstriction during acute severe asthma.
\end{abstract}

(Thorax 1994;49:492-495)

The renin-angiotensin system plays an important part in the regulation of cardiovascular homoeostasis and electrolyte balance. ${ }^{1}$ The effector hormone of the system is the octapeptide angiotensin II (AII) which is a potent vasoconstrictor of vascular smooth muscle and a stimulus for the secretion of aldosterone from the adrenal gland. ${ }^{2}$ In addition, recent in vitro work has shown that AII can potentiate bronchoconstriction of rabbit airway smooth muscle, ${ }^{3}$ although the direct effects of AII on bronchomotor tone and reactivity in man have not previously been described.

In a preliminary study we found evidence of considerable activation of the renin-angiotensin system in acute severe asthma. We therefore measured plasma levels of renin and AII in a group of patients with acute severe asthma and compared the results with those obtained in patients with stable chronic asthma and a non-asthmatic control group. Since AII may have several potentially adverse effects on pulmonary function, including bronchoconstriction, we were also interested in examining the effect of AII on lung function in vivo in mild asthmatic patients.

\section{Methods}

STUDY 1: ACTIVITY OF THE RENIN-ANGIOTENSIN SYSTEM IN ACUTE SEVERE ASTHMA

Plasma levels of renin and AII were measured in four groups of subjects. Group 1 comprised 20 patients (six men) of mean (SD) age 34 (12.9) years admitted non-consecutively (two patients admitted twice) to Accident and Emergency with acute severe asthma (PEF 125 (38) $1 / \mathrm{min}, \mathrm{PaO}_{2} 9 \cdot 2(3.3) \mathrm{kPa}$ (on air), pulse rate 120 (15) beats/min on admission). Venous blood was withdrawn shortly after admission for estimation of plasma renin and AII levels and measurements were repeated on days 2 and 5 after admission. All had received nebulised $\beta_{2}$ agonists (salbutamol) and four were given intravenous hydrocortisone in Accident and Emergency prior to venesection. Seventeen patients were taking regular inhaled corticosteroids, five oral theophylline, and 10 were on oral prednisolone. All used as required inhaled $\beta_{2}$ agonists via a metered dose inhaler (six were also taking $\beta_{2}$ agonists via home nebuliser), four inhaled salmeterol, and four inhaled ipratropium bromide. No patients were on oral $\beta$ agonists. Only one patient was on regular oral diuretic therapy. Group 2 comprised nine patients (two men) of mean (SD) age 40.3 (13) years with mild chronic asthma (PEF 450 (59) $1 /$ min, mean $\mathrm{O}_{2}$ saturation 96.8 $(1 \cdot 2) \%)$. All were taking as required inhaled $\beta_{2}$ agonists via a metered dose inhaler and six were receiving regular inhaled corticosteroids. Group 3 consisted of 10 patients (two men) of mean (SD) age 39.3 (15) years with severe chronic asthma taking regular nebulised $\beta$ agonists (salbutamol) (PEF 225 (48) $1 / \mathrm{min}, \mathrm{O}_{2}$ saturation $97(1 \cdot 8) \%)$. In addition all were taking regular inhaled corticosteroids, four nebulised ipratropium bromide, three oral theophylline, and three maintenance doses of oral prednisolone. Group 4 comprised 16 normal volunteers (five men) of mean age 36.6 (11.4) years, PEF 507 (77) $1 / \mathrm{min}, \mathrm{O}_{2}$ saturation $98(1 \cdot 3) \%$. Patients in groups 2 and 3 withheld $\beta_{2}$ agonists for six hours before venesection. 
STUDY 2: EFFECT OF INTRAVENOUS ANGIOTENSIN II ON LUNG FUNCTION IN ASTHMA

Eight mild asthmatic patients (four men) of mean (SD) age $34(6.4)$ years (mean FEV 185 $(12.5) \%$ predicted) were studied. All were taking inhaled short acting $\beta_{2}$ agonists and seven of the eight were also taking regular inhaled corticosteroids. Inhaled $\beta_{2}$ agonists were withheld for six hours prior to each visit while corticosteroid therapy continued unchanged.

Patients attended the laboratory on two separate study days. A 24 hour collection of urine was obtained before each visit as an indirect means of assessing dietary sodium intake. On arrival two indwelling cannulae (Venflon) were inserted into forearm veins for the purposes of blood sampling and administration of the intravenous infusion. Patients were asked to rest for a period of 20 minutes, following which blood pressure and baseline spirometric measurements were recorded. Thirty $\mathrm{ml}$ venous blood was withdrawn for estimation of baseline plasma levels of renin, AII, and potassium. Each patient then received either angiotensin II $(2,4$, and $8 \mathrm{ng} / \mathrm{kg} / \mathrm{min}$ in increasing increments at 30 minute intervals) or placebo ( $5 \%$ dextrose). This was delivered intravenously by means of a $50 \mathrm{ml}$ syringe driver (Perfusor Secura E, B Braun Melsunger AG, Germany). At the end of each 30 minute infusion period spirometric values were measured (best of three readings) and blood withdrawn at the same time points for estimation of plasma renin, AII, and serum potassium concentrations. Patients remained semirecumbent for the duration of the study. Oxygen saturation was monitored continuously throughout the study period.

The study was approved by the Glasgow West ethical committee and informed consent was obtained from all participants. Subjects with known hypertension or those taking regular diuretic therapy were excluded.

Drugs were prepared in the sterile unit of our pharmacy and administered according to a randomised, double blind, crossover design.

\section{MEASUREMENTS}

Spirometric values were recorded with a dry wedge spirometer (Vitalograph, Buckinghamshire, UK) and the best of three readings were recorded at each time point. Oxygen saturation was monitored by a pulse oximeter and finger probe (Ohmeda Biox 3700E). Blood pressure was measured with a semi-automatic sphygmomanometer (Dinamap, 1846 FX Vital Signs Monitor; Critikon, Berkshire, UK) and the mean of three readings at each time point was recorded.

To measure plasma concentrations of renin and AII blood samples were separated by centrifugation and the plasma frozen at $-20^{\circ} \mathrm{C}$ until hormone analysis. The assay for angiotensin II is a modified radioimmunoassay which uses $\mathrm{C}_{18}$ cartridges (Sep-Pak; Waters, Milford, Massachusetts, USA) to extract angiotensin II from plasma. ${ }^{4}$ The intra-assay coefficient of variation is $6.4 \%$ and interassay variation $10 \%$. The normal range for our laboratory is $3-12 \mathrm{pg} / \mathrm{ml}$. The assay for renin is the method developed by Millar et al ${ }^{5}$ which measures plasma renin concentration rather than plasma renin activity, and is based on antibody trapping. The intra-assay range is $5.5 \%$ and interassay range $11 \%$. The normal range for our laboratory is $9-50 \mu \mathrm{U} / \mathrm{ml}$.

Serum potassium levels were measured with standard ion selective electrodes.

\section{STATISTICAL ANALYSIS}

Differences in plasma concentrations of renin and AII between the groups in study 1 were evaluated with the Mann-Whitney $U$ test. In study 2 comparison of baseline values and the significance of changes in these at each time point was by analysis of variance. $p$ values $<0.05$ were considered significant.

\section{Results}

STUDY 1: ACTIVITY OF THE RENIN-ANGIOTENSIN SYSTEM IN ACUTE SEVERE ASTHMA

In the acute asthma group, mean (interquartile range) plasma concentrations of renin $(\mu \mathrm{U} / \mathrm{ml})$ were significantly elevated $(\mathrm{p}<0.05)$ on day 1 $[48 \cdot 7(24-79)]$, day $2[44 \cdot 2(15-75)]$, and day 5 [45.5 (21-70)] when compared with the patients with severe chronic asthma [22 (17$32)]$, mild chronic asthma [19 (12.5-25.5)], or the control group [20 (12-43)] (fig 1). Plasma AII concentrations $(\mathrm{pg} / \mathrm{ml})$ were elevated (significantly at day 5 only, p $<0.05)$ on day $1[32.5$ (7.7-75)], day 2 [38 (6-105)], and day 5 [56 (12109)] when compared with the patients with severe chronic asthma [12.2 (7.7-18.8)], mild chronic asthma [12.5 (6-19.5)], or the control group [11.3 (9-17)] (fig 1). There was no significant difference in plasma levels of renin and AII when severe chronic asthma, mild chronic asthma, and control groups were compared.

STUDY 2: EFFECT OF INTRAVENOUS ANGIOTENSIN II ON LUNG FUNCTION IN ASTHMA

Plasma AII concentrations

At $0,30,60$, and 90 minutes the mean (SD) plasma levels of AII were 12.4 (5.3), $25 \cdot 1$ (4.0), $55.9(10.2)$, and $121.3(20 \cdot 2) \mathrm{pg} / \mathrm{ml}$, respectively after infusion of AII $(2,4$, and $8 \mathrm{ng} / \mathrm{kg} /$ $\mathrm{min}$ ), and $12 \cdot 8(7 \cdot 9), 12 \cdot 2(8 \cdot 0), 11 \cdot 1(6.9)$, and $11.5(6.3) \mathrm{pg} / \mathrm{ml}$ after infusion of placebo (fig 2).

\section{Blood pressure and heart rate}

Blood pressure did not change significantly during infusion of placebo. Following infusion of AII, however, there were significant rises $(\mathrm{p}<0.05)$ in both systolic (fig 2) and diastolic levels. There were no significant changes in heart rate during infusion of placebo or AII (data not shown).

\section{FEV}

There was no significant difference between baseline $\mathrm{FEV}_{1}$ on either study day. Mean (SE) baseline values of $\mathrm{FEV}_{1}$ were $2.55(0.64)$ and $2.63(0.34)$ litres before infusion of AII and 

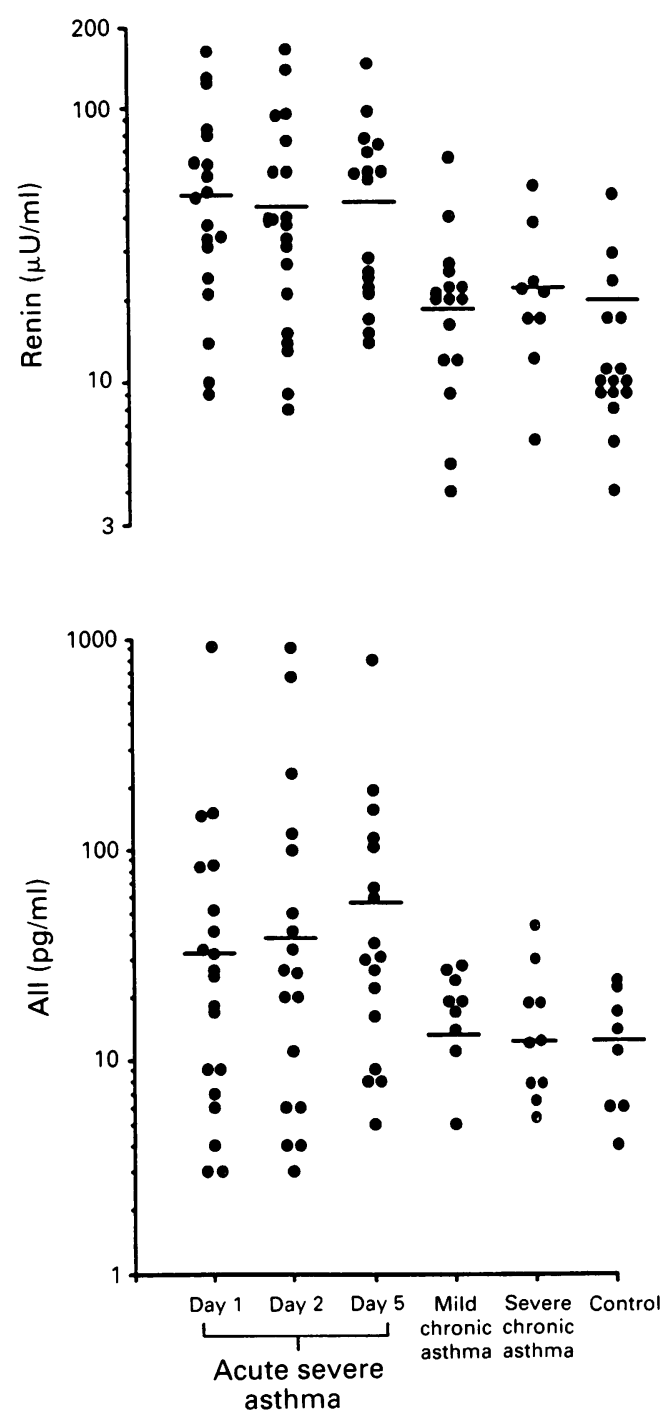

Figure 1 Scatter plot (log scale) illustrating individual plasma levels of renin and angiotensin II ( $A I I)$ in acute severe asthma $(n=20)$, mild chronic asthma $(n=9)$, severe chronic asthma $(n=10)$, and controls $(n=16)$. Bars $=$ medians.

placebo respectively. A significant bronchoconstrictor response to AII was observed at 60 and 90 minutes with a mean (SE) fall in $\mathrm{FEV}_{1}$ from baseline values of $0.18(0.03)$ and 0.34 $(0.13)$ litres $(7.8(2.02) \%$ and $12.4(3.3) \%$, respectively) compared with $0.02(0.09)$ and $0.01(0.09)$ litres $(0.3(1.3) \%$ and $0.6(1.2) \%)$ after placebo (fig 2). In addition, five of the eight patients reported cough or chest tightness during the final infusion period.

\section{Oxygen saturation}

Mean (SE) baseline oxygen saturation was normal on each study day $(97.5(0.3) \%$ before infusion of AII and $97.5(0 \cdot 2) \%$ before placebo). Oxygen saturation did not alter significantly during infusion of placebo or AII (data not shown).

\section{4 hour urinary sodium concentrations}

There were no significant differences between 24 hour urinary sodium concentrations on either of the study days. Mean (SE) 24 hour urinary sodium values were $178(25 \cdot 2)$ and 145
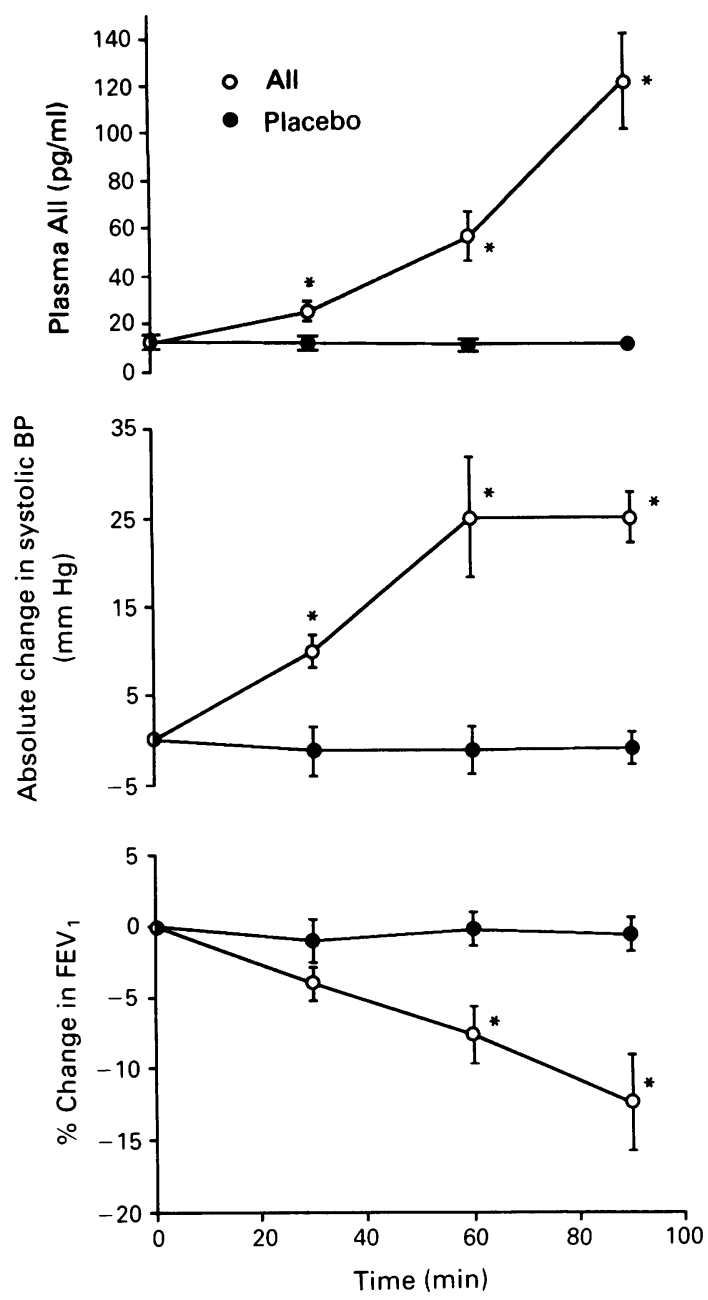

Figure 2 Mean ( $S E$ ) plasma levels of $A I I(\mathrm{pg} / \mathrm{ml})$, change in systolic $B P(\mathrm{~mm} \mathrm{Hg})$, and change in $F E V$, $(\%)$ from baseline values $(n=8) .{ }^{*} p<0.05 \mathrm{v}$ placebo.

(21.2) $\mathrm{mmol} / 24$ hours before infusion of AII and placebo respectively.

\section{Discussion}

Our investigation has revealed activation of the renin-angiotensin system in those patients with acute severe asthma when compared with the non-asthmatic control group and those with mild chronic asthma or severe chronic asthma who had withheld $\beta$ agonist therapy. Plasma renin levels were noted to be significantly elevated on days 1,2 , and 5 after admission, and although AII levels were also elevated, this only reached statistical significance on day 5. It is possible, however, that the lack of significance on the first two days may be the result of the small sample size. The reason for the wide range of variations in plasma levels of renin and AII in the patients is unclear, but it may be related to differences between individuals in factors influencing the renin-angiotensin system.

Since $\beta$ adrenoceptors are known to be present on juxtaglomerular cells, ${ }^{1}$ nebulised $\beta_{2}$ agonist therapy used in the treatment of acute asthma may be responsible for this activation. In support of this suggestion was our observation that plasma levels of renin and AII remained elevated on days 2 and 5 when the patients were recovering from the acute attack 
of asthma (as demonstrated by increased peak flow rates) but still receiving nebulised bronchodilator therapy. In addition, Phillips et $a l^{6}$ observed an increase in plasma renin activity following intravenous infusion of salbutamol in four healthy male subjects, and Scheinin et $a l^{\top}$ found a dose dependent increase in plasma levels of renin after both fenoterol and salbutamol administered by metered dose inhaler to six normal subjects.

Hypoxia may also cause activation of the renin-angiotensin system, although studies which have examined this effect in animals and in man have produced conflicting results. Rats exposed to chronic hypoxia develop a rise in renin and renin substrate, ${ }^{8}$ although hypoxia has been reported to reduce the ability of the lung to convert angiotensin I to angiotensin II in anaesthetised dogs. ${ }^{9}$ In stable cor pulmonale the renin-angiotensin system has been reported not to be activated, ${ }^{10}$ while others have observed elevated levels of AII in patients with airflow obstruction and arterial hypoxaemia. ${ }^{11}$

Other stimuli which could cause activation of the renin-angiotensin system in acute severe asthma include circulating catecholamines. Ind et al have reported elevated noradrenaline levels in acute asthma, although adrenaline levels appear to rise only in the most severe cases. ${ }^{12}$ We have not found evidence of this in our study where plasma catecholamines were in the normal range (data not shown). Other stimuli are hypovolaemia and drugs such as diuretics. However, none of our patients with acute asthma was clinically dehydrated and only one was taking regular oral diuretic therapy. The role of other inflammatory mediators on the activity of the renin-angiotensin system - for example, histamine or prostaglandins - is unclear, although it is of interest that proteinases secreted by mast cells have been shown rapidly to convert angiotensin I to angiotensin II by an angiotensin converting enzyme independent pathway. ${ }^{13}$

AII has recently been shown to potentiate vagal mediated contraction of rabbit airway smooth muscle through the activation of prejunctional receptors, ${ }^{3}$ thus raising the possibility that it may have bronchoconstrictor activity in the human airway. In our second study we showed that AII causes bronchoconstriction when administered intravenously to mild asthmatic patients. The exact mechanism of bronchoconstriction by AII is uncertain, but could be either a direct effect on airway smooth muscle or perhaps even the result of release of other mediators of bronchoconstriction such as endothelin. ${ }^{14}$ Another possible mechanism is a reflex increase in vagal tone secondary to the rise in blood pressure, although it is interesting to note that heart rate did not increase in our study. As the range of plasma levels of AII achieved during the infusions is comparable to that found in our acute asthma study, we could therefore hypothesise that this hormone may contribute to a proportion of the bronchoconstriction in acute severe asthma.
It is interesting to consider further how AII could have potential adverse effects on the asthmatic airway. AII is also known to cause pulmonary vasoconstriction and hypoxaemia ${ }^{15}$ which could contribute to ventilation-perfusion imbalance during acute asthma or cause reduced clearance of inflammatory mediators. Other reported actions of AII include increased vascular permeability in experimental animals, raising the possibility that elevated levels of this hormone in asthma could contribute to the inflammatory response within the airway. AII has also been reported to promote the growth of cultured vascular smooth muscle cells in vitro. ${ }^{16}$ If such effects occurred on airway smooth muscle as a result of generation of excess angiotensin II in the lungs, this may be of importance in the long term by contributing to the development of airway smooth muscle hypertrophy.

In conclusion, we have observed activation of the renin-angiotensin system in patients with acute severe asthma and have also shown that this hormone causes bronchoconstriction in vivo in man. These observations pose the hypothesis that AII may contribute to bronchoconstriction during acute severe asthma.

This work was supported by the National Asthma Campaign The authors wish to thank Ms Wendy Fallon for her help with drug preparation and blinding of the studies.

1 Reid IA, Morrice BJ, Ganong WF. The renin angiotensin system. Annu Rev Physiol 1978;40:377-410.

2 Paul M, Bachmann J, Ganten D. The tissue renin angiotensin systems in cardiovascular disease. Trends Cardiovasc Med 1992;2:94-9.

3 Yamawaki I, Tamaoki J, Horii S, Yamauchi F, Takizawa T. Angiotensin II potentiates neurally mediated contraction of rabbit airway smooth muscle. Am Rev Respir Dis 1991;143:A343.

4 Morton JJ, Webb DJ. Measurement of plasma angiotensin II. Clin $S_{c i}$ 1985;68:483-4.

5 Millar LA, Leckie BJ, Morton JJ, Jordan J, Tree M. A micro assay for active and total renin concentration in human plasma based on antibody trapping. Clin Chim Acta 1980;101:5-15.

6 Phillips PJ, Vedig AE, Jones PL, Chapman MG, Collins $\mathrm{M}$, Edwards JB, et al. Metabolic and cardiovascular side $M$, Edwards JB, et al. Metabolic and cardiovascular side
effects of the $\beta$ adrenoceptor agonists salbutamol and effects of the $\beta$ adrenoceptor agonists salbutam
rimiterol. Br $\mathcal{F}$ Clin Pharmacol 1980;9:483-91.

7 Scheinin M, Koulu M, Laurikanein E, Allonen H. Hypokalaemia and other non-bronchial effects of fenoterol and salbutamol: a placebo-controlled dose-response study in healthy volunteers. Br $\mathcal{F}$ Clin Pharmacol 1987;24:645-53.

8 Gould AB, Goodman SA. The effect of hypoxia on the renin-angiotensin system. Lab Invest 1970;22:443-7.

9 Szidon P, Bairney N, Oparil S. Effect of acute hypoxia on the pulmonary conversion of angiotensin I to angiotensin II in dogs. Circ Res 1980;46:221-6.

10 Neilly JB, Clark CJ, Tweddel A, Rae AP, Hughes DM, Hutton I, et al. Transpulmonary angiotensin II formation in patients with chronic stable cor pulmonale. Am Rev in patients with chronic stabi
Respir Dis 1987;135:891-5.

11 Peacock AJ, Matthews A. Transpulmonary angiotensin II formation and pulmonary haemodynamics in stable hypoxic lung disease: the effect of captopril. Respir Med 1992;86:21-6.

12 Ind PW, Causon RC, Brown MJ, Barnes PJ. Circulating catecholamines in acute asthma. BMF 1985;290:267-9.

13 Reilly CF, Tewksbury DA, Schechter NM, Travis J. Rapid conversion of angiotensin I to angiotensin II by neutrophil and mast cell proteinases. $f$ Biol Chem 1982;257:8619-22.

14 Kohno M, Horio T, Yokokawa K, Kurihara N, Taheda T. C-type natriuretic peptide inhibits thrombin and angiotensin II-stimulated endothelin release via cyclic 320-5.

15 Raff HJ, Maselli J, Reid JA. Correlation of plasma angiotensin II concentration and plasma renin activity during acute hypoxia in dogs. Clin Exp Pharmacol Physiol 1985;12:91-4.

16 Campbell-Boswell M, Robertson AL. Effect of angiotensin II and vasopressin on human smooth muscle cells in vitro. Exp Mol Pathol 1981;35:265-76. 